\title{
AS CONCEPÇÕES DE PROFISSIONAIS DA EDUCAÇÃO INFANTIL SOBRE QUALIDADE DA EDUCAÇÃO
}

\section{THE CONCEPTIONS OF PROFESSIONALS OF CHILD EDUCATION ON QUALITY OF EDUCATION}

\author{
Wanessa Maria de Lima ${ }^{1}$ \\ Joseana Maria Saraiva $^{2}$
}

\section{Resumo}

O estudo remete a um tema clássico na área da educação - a qualidade da educação explorado por diversos estudiosos. Tem como objetivo apresentar as concepções dos gestores e dos profissionais das Instituições de Educação Infantil do Recife-PE sobre qualidade da educação e os fatores que se interpõem as expressivas limitações em relação à qualidade da educação em seus vários aspectos. Trata-se de um estudo de caso, de abordagem qualitativa, de caráter explicativo. Evidenciou-se limitações no campo do entendimento do que seja qualidade da educação e entraves que passam, sobretudo, pela efetivação do direito a qualidade da educação.

Palavras-chave: Representações Sociais; Profissionais; Qualidade da Educação

\begin{abstract}
The study refers to a classical theme in education - the phenomena of quality of education - researched by many scholars. In this perspective, this article's objective is to present the conceptions of managers and professionals from Recife-PE preschool institutions on quality of education and the factors which interfere in the problem of the expressive limitations to the quality of education in its many aspects. This is a case study with a qualitative approach and of explanatory character. Limitations not only in the field of understanding what quality of education is but also on hindrances related to the effecting of the right to quality of education as a right pertaining to all and not just a few were detected.

\footnotetext{
${ }^{1}$ Professora de Educação Infantil e do Ensino Fundamental da Prefeitura de Vitória de Santo Antão-PE. Economista Doméstica e Pedagoga. Mestra em Consumo, Cotidiano e Desenvolvimento Social / UFRPE. Membro do Núcleo de Estudos e Pesquisa em Políticas Públicas para Infância e Adolescência/ NEPIAD/UFRPE. Endereço: Rua Manoel de Medeiros, s/n - Dois Irmãos, Recife - PE, CEP. 52171-900, Brasil. Telefone: (81) 99600-6468. Email: wanessaefed@ yahoo.com.br.

${ }^{2}$ Professora do Programa de Pós-graduação em Consumo, Cotidiano e Desenvolvimento Social (PGCDS/ UFRPE). Mestra em Nutrição Saúde Pública e Doutora em Serviço Social. Coordenadora do Núcleo de Estudos e Pesquisa em Políticas Públicas para Infância e Adolescência - NEPIAD / UFRPE. Endereço: Rua Manoel de Medeiros, s/n - Dois Irmãos, Recife - PE, CEP. 52171-900, Brasil. Telefone: (81) 3320-6535. Email: joseanasaraiva@yahoo.com.br.
}

Revista de Administração Educacional, Recife, V. 1. No 2 - jul/dez. 2017 p. 88-105 
Keywords: Social representations; Professionals; Quality of Education

\section{INTRODUÇÃO}

A produção bibliográfica sobre a discussão do termo qualidade é unânime em afirmar que se trata de uma categoria de estudo complexa, que envolve subjetividades, visões, valores e créditos, de difícil conceituação e passível de múltiplas interpretações. Porém, para os estudiosos da qualidade da educação (Zabalza, 1998; Moss, 2002; MEC, 2003; Davok, 2007; Campos, 2013; Gentilli, 2015, dentre outros), o processo de compreensão desse conceito é essencial no campo educacional, visando embasar os estudos e as práticas, bem como os critérios, as dimensões e os fatores que demarcam a constituição de uma educação de qualidade.

Para este grupo de estudiosos, o método de compreensão desse conceito na área da educação exige uma análise da sua evolução com vistas delimitar no tempo e no espaço o desenvolvimento desse fenômeno que vem se alterando, apresentado traços distintos conforme as demandas e as exigências, econômicas, políticas, sociais e culturais de cada período na história. Nessa direção, o enfoque da qualidade da educação, tem evoluído à medida que as relações sociais e econômicas do homem com a natureza tornam-se mais complexas.

Segundo Dourado e Oliveira (2009, p.203) qualidade é um conceito socialmente construído que vem se alterando no tempo e no espaço e se vincula às necessidades e exigências sociais. $\mathrm{Na}$ antiguidade Aristóteles já tratava desse fenômeno dando ênfase à educação pública e de qualidade, a cargo do Estado e igual para todos os cidadãos. Na Idade Média, o foco do conceito de qualidade é na educação profissional que vai ao encontro das necessidades da sociedade de consumo mercantilista emergente. Na modernidade, a importância de considerar a qualidade da educação fundamenta-se, inicialmente, no pensamento de Comenius, que revela inquietação com a qualidade na educação, desde a didática das línguas e das ciências até a organização das escolas, com o plano ambicioso de uma profunda reforma de todas as escolas. Corroborando as ideias de Comenius, os marxistas, com base na dialética, chamam a atenção para a passagem da

Revista de Administração Educacional, Recife, V. 1. № 2 - jul/dez. 2017 p. 88-105 
quantidade para a qualidade, através da qual as mudanças em um ser, especialmente na sua quantidade ou na sua forma, podem produzir um salto de qualidade que supera o anterior, distinguindo-o mediante um diferenciador, a qualidade.

Na Idade Contemporânea, mais especificamente a começar da década de 1940, o conceito de qualidade, do ponto de vista da qualidade total, como filosofia que fundamenta a administração dos negócios das empresas, passa a ser amplamente discutido e difundido em nível mundial, incorporado em programas técnicos de produção, controle e gestão, em busca de um padrão de qualidade para os produtos e os serviços prestados à época, visando o atendimento pleno das necessidades do cliente (HERÉDIA, 1997, p. 98). A concepção prevalente dessa filosofia é que Qualidade Total é uma ferramenta gerencial na condução dos negócios de uma empresa que deve ser aplicada a todas as áreas e níveis, devendo sempre começar do topo, com o comprometimento total da alta administração (HARGRAVES et.al., 2007, p. 6).

Na década de 1960 este conceito passa a ser utilizado não apenas no contexto das organizações privadas, sendo apreendido também pelos mais diversos setores da sociedade, inclusive por parte dos educadores, tanto de escolas públicas como particulares, introduzindo novos padrões de produção, de consumo, de conhecimento, formas culturais e práticas políticas que, progressivamente, foram transportadas para as políticas públicas da área da educação como discurso oficial (ALVES, 2012, p.2). Discurso que se caracteriza declaradamente como de cunho conservador e de sentido que hegemoniza a lógica do capital no cenário latino-americano contemporâneo.

Seguindo esta tendência, na década de 1970, o debate da qualidade é marcado pela dualidade qualidade versus quantidade. $O$ enfoque da quantidade defende a democratização do acesso, a expansão das oportunidades de educação na rede pública para os menos favorecidos, enquanto o enfoque da qualidade era identificado como proposta elitista, mais especificamente, qualidade para poucos (CARREIRA, 2007, p. 20). Surgem no país, fundamentado neste contexto, os sinais mais claros da influência neoliberal na educação, o início da privatização da educação brasileira, cujo mercado deveria substituir o papel do Estado como provedor da educação pública. A proposta é reduzir os gastos com

Revista de Administração Educacional, Recife, V. 1. No 2 - jul/dez. 2017 p. 88-105 
as políticas públicas, sobremodo, o incentivo a livre competição do mercado no campo da educação.

No final dos anos 80 foi aprovada a nova Constituição Federal (1988) que representou um marco em termos de democracia na garantia de direitos. No seu artigo 205, que trata da educação, afirma que esta deve ser concebida como direito de todos e dever do Estado e da família. No artigo IV, trata da garantia do direito ao atendimento em creche e pré-escola às crianças de zero a seis anos de idade, complementando a ação da família, como dever do Estado. Porém, contrariando essa perspectiva, o Brasil adota as políticas de ajuste econômico que impõem restrições às políticas sociais, em conformidade com as predeterminações do Neoliberalismo.

Nessa condição, a qualidade da educação se incorpora à agenda do debate neoliberal na conjuntura das reformas educativas, concebida como mera busca de eficiência. A preocupação do Estado era promover o melhor desempenho da educação com redução dos gastos, poucos recursos, muitas metas e, assim, nessa direção, as técnicas empresariais e a qualidade total foram adotadas efetivamente nas redes de ensino públicas do país.

Segundo Campos (2013, p.26), nessa mesma década, a massa de dados gerada pelos sistemas de avaliação centralizados possibilitou a realização de estudos que puseram a nu as desigualdades do acesso ao conhecimento por parte de alunos com diferentes origens sociais, evidenciando processos de discriminação e de esforços de desigualdades que persistem na escola até os dias atuais.

Como resultado desse sistema de avaliação, no final dos anos de 1990, mais especificamente, no último ano, brota a Campanha Nacional pelo Direito a Educação impulsionada por um conjunto de organizações da sociedade civil, no contexto preparatório do processo para a Cúpula Mundial de Educação, realizada em Dacar, no Senegal, em 2000. Segundo Carreira e Pinto (2007, p. 73), a articulação surge com o desafio de somar diferentes forças políticas pela efetivação dos direitos educacionais garantidos por lei, que determina que todo cidadão e toda cidadã tenham acesso a uma educação pública de qualidade. Nessa direção, a Campanha visa disseminar amplamente o conceito de educação enquanto direito social, focalizando a qualidade, o financiamento e a

Revista de Administração Educacional, Recife, V. 1. № 2 - jul/dez. 2017 p. 88-105 
gestão democrática da educação, bem como o reconhecimento de seus profissionais (CAMPOS, 2006, p. 13).

Em 1990, realizou-se em Jomtien - Tailândia - a Conferência Mundial de Educação para Todos, que definiu um amplo conjunto de desafios a serem enfrentados de modos diversos pelos sistemas educacionais ao redor do mundo. Como consequência dessa conferência, em 2000, 164 países, inclusive o Brasil, se reuniram em Dakar-Senegal na chamada global à ação Cúpula Mundial de Educação para avaliar as metas estabelecidas na Conferência Mundial de Educação e propor uma agenda comum de políticas de Educação para Todos (EPT) visando o fortalecimento da cidadania e o incentivo a habilidades necessárias a um desenvolvimento humano pleno e sustentável. Nessa reunião, foram acordados seis objetivos a serem perseguidos por todos os países signatários tencionando prover os meios para melhorar as condições de vida de crianças, jovens e adultos por meio da educação para todos, gratuita e com a garantia da qualidade. Tais objetivos estão relacionadas ao cuidado e à Educação Infantil, ao Ensino Fundamental universal e à qualidade da educação (RABELO; SEGUNDO;JIMENEZ, 2009, p. 7-9).

Ao assumir tais objetivos, o Brasil passou a integrar o conjunto de países empenhados na conquista das metas de Educação Para Todos com a garantia de ser gratuita de qualidade. A proposta, conforme encaminhamentos do Compromisso de Dakar, é que haja engajamento efetivo do Brasil, na perspectiva de propor mudanças importantes no perfil das políticas públicas desenvolvidas no país. Os resultados destas mudanças foram apresentados por cada país no Fórum Mundial de Educação (World Education Forum WEF 2015),em Incheon, na Coréia do Sul, organizado pela UNESCO, com a participação de mais de 130 Ministros de Educação e mais de 1.500 participantes, entre organizações de sociedade civil, agências bilaterais e multilaterais, professores, ativistas e experts.

Nesses termos, o Fórum acordou a nova agenda da educação, que irá vigorar entre 2015 e 2030, que afirma a importância da educação como principal impulsionador do desenvolvimento e reforça o compromisso de garantir educação inclusiva, equitativa e de qualidade para todos e não para poucos.

Nesse contexto, segundo o Fórum Mundial de Educação (2015, p.2) a educação de qualidade passa a ser entendida como condição imprescindível para promover criatividade

Revista de Administração Educacional, Recife, V. 1. № 2 - jul/dez. 2017 p. 88-105 
e o conhecimento e também assegura a aquisição de habilidades básicas em alfabetização e matemática, bem como habilidades analíticas e de resolução de problemas, habilidades de alto nível cognitivo e habilidades interpessoais e sociais. Além disso, ela desenvolve habilidades, valores e atitudes que permitem aos cidadãos levar vidas saudáveis e plenas, tomar decisões conscientes e responder a desafios locais e globais por meio da educação para o desenvolvimento sustentável e da educação para a cidadania global.

Entende-se que, a compreensão desse conceito deve se dá de forma participativa e democrática, uma vez que o processo propicia espaço para partilhar ideias, valores, visões, conhecimentos e experiências. Para tanto, deve envolver grupos diferentes que integram a escola, incluindo gestores, profissionais, alunos, famílias, profissionais, se considerar os fatores de contexto presentes em cada situação, que atendam às necessidades e demandas dos sujeitos usuários. No campo da educação infantil, esta compreensão parece ser categórica para evidenciar o significado dos problemas constatados pelos estudos. Entretanto, diferentes e complexas questões carecem de ser levantadas visando subsidiar as reflexões que vêm sendo feitas acerca desta temática, que devem resultar em critérios, ideias, sugestões e críticas para a ampliação e melhoria de um trabalho que se paute pela qualidade e viabilize concretamente o alcance da qualidade da Educação Infantil como direito de todos.

Partindo desses pressupostos, o objetivo deste estudo é analisar o conceito de qualidade da educação, com base nas representações sociais de gestores e educadores da educação infantil, considerando suas múltiplas significações, dimensões, horizontes teórico-históricos fundamentais para o entendimento da qualidade da educação como uma condição básica para todos, como direito social. Mais especificamente, analisar as representações sociais das Gestoras, das Coordenadoras Pedagógicas, das Professoras e das Auxiliares de Desenvolvimento Infantil, o que pensam, como percebem e que expectativas desenvolvem a respeito da qualidade da educação.

Entende-se que apreender as representações sociais desses sujeitos sobre qualidade da educação torna-se fundamental, uma vez que refletem o que pensam, seus atos e suas práticas sociais. Nessa direção, de acordo com os objetivos do estudo, a pesquisa foi realizada com os gestores e coordenadores pedagógicos de creches, pré-escolas e Centros

Revista de Administração Educacional, Recife, V. 1. No 2 - jul/dez. 2017 p. 88-105 
Municipais de Educação Infantil da rede municipal de Recife-PE e com os/as professores/as e os/as auxiliares de desenvolvimento infantil.

\section{METODOLOGIA}

\section{Universo e amostra}

Quanto ao universo da pesquisa, conforme o Plano Plurianual (2014-2017) e de acordo com a relação de Creches e Pré-escolas e CMEIs da Rede Municipal da Prefeitura do Recife (Secretaria de Educação, 2016 s/p) existem hoje na rede 800 professores/as, 73 gestores/as - coordenadoras pedagógicas de creches, pré-escolas e CMEIs e 680 auxiliares de Educação Infantil (ADIs) distribuídos/as em atividade na rede (PREFEITURA MUNICIPAL DE RECIFE, 2015, p.1).

O Município de Recife é dividido em 6 (seis) Regiões Político-Administrativas RPA's para efeito de formulação, execução e avaliação permanente das políticas públicas e do planejamento governamental (Lei no 16.293/97). Os Centros Municipais de Educação Infantil e as respectivas creches e pré-escolas encontram-se distribuídos nestas 6 (seis) RPA's.

Desse modo, e levando em consideração esta distribuição, foram selecionados para a coleta de dados 1 Centro Municipal de Educação Infantil e 1 creche e pré-escola em cada RPA, contemplando em seus respectivos quadros de pessoal, 1 gestor, 1 coordenador pedagógico, 12 professores e 12 auxiliares de desenvolvimento infantil diretamente envolvidos com as atividades de cuidados e educação da criança. Contabilizaram-se, desta forma, 6 CMEIs e 6 creches e pré-escolas, totalizando 12 equipamentos coletivos de atendimento à criança, os quais empregam trabalhadores/as, distribuídos/as nas três categorias selecionadas: 6 gestores/as; 06 coordenadores/as pedagógicos/as; 12 professores/as; 12 auxiliares de educação infantil, totalizando a amostra de 36 profissionais que participaram da pesquisa.

\section{Instrumentos e coleta de dados}

Para coleta de dados se utilizou a entrevista estruturada como técnica principal de coleta de dados. Além disso, considerou-se os relatos, registros e observações que permitiram um retrato abrangente e detalhado do fenômeno social estudado. Para tanto, o

Revista de Administração Educacional, Recife, V. 1. No 2 - jul/dez. 2017 p. 88-105 
instrumento de coleta de dados se constituiu de um formulário de entrevista composto por um conjunto de perguntas abertas, constituindo-se o pré-teste um momento oportuno e útil para revisar o método de pesquisa.

\section{Analise dos dados}

A fim de compreender as interpretações, ideias, visões e concepções que os gestores públicos, professores e auxiliares de educação infantil possuem a respeito da problemática sobre qualidade da educação e os fatores considerados para promoção da qualidade da educação, insere-se neste estudo o conceito das representações sociais, utilizado em várias áreas do conhecimento de Moscovici. Para esse autor as representações sociais se constituem em uma das formas de compreensão da realidade, do mundo concreto, permitindo encontrar elementos do discurso social trazido pelos sujeitos sociais para melhor compreensão dos fenômenos sociais (MOSCOVICI, 2015, p.123).

\section{RESULTADOS E DISCUSSÃO}

As representações sociais aparecidas na Tabela 1 refletem a multidimensionalidade que o termo qualidade da educação apresenta a partir dos valores, crenças, visões, concepções e experiências que as gestoras, as coordenadoras pedagógicas, as professoras e as auxiliares de instituições de Educação Infantil possuem acerca dessa condição. Entre outros aspectos entrelaçados, a perspectiva dos sujeitos envolvidos na pesquisa sobre o debate da qualidade da educação e os aspectos/fatores considerados para promoção da qualidade da educação.

Nessa direção, as representações sociais dos sujeitos sobre qualidade da educação e os fatores que se interpõem a sua efetivação, constituem-se como elementos fundamentais para melhor compreensão do fenômeno estudado, permitindo desvendar o que os sujeitos, agentes da educação infantil, pensam sobre esta condição.

TABELA 1 - Representações sociais das gestoras, das coordenadoras pedagógicas, das professoras e das auxiliares de instituições de Educação Infantil sobre qualidade da educação, o debate sobre qualidade da educação e os aspectos/fatores considerados para promoção da qualidade da educação - Recife, 2016. 


\section{Representações sociais}

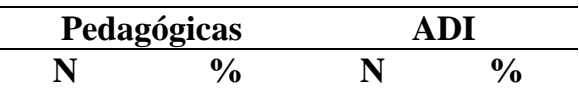

O que entende sobre qualidade da educação?

É aquela que é boa (que tem eficiência; que tem excelência; tem eficácia; funciona perfeitamente);

Envolve estrutura física, material e pessoal qualificado;

É aquela que oferece alimentação, saúde, bem-estar para as crianças;

É mostrar um bom serviço (bom atendimento);

Não sabe responder;

$\begin{array}{llll}5 & 35,71 & 9 & 32,14\end{array}$

$3 \quad 21,42 \quad 4 \quad 14,28$

$3 \quad 21,42 \quad 7 \quad 25,00$

$\begin{array}{lccc}1 & 7,14 & 3 & 10.71 \\ 2 & 14,28 & 5 & 17,85\end{array}$

TOTAL

14

$100,0 \quad 28$

100,0

Como avaliam o debate sobre a qualidade da educação?

Existe na teoria, mas, não existe na prática (é utopia);

Não sabe responder

Só existe no debate (se fala muito, mas, nada acontece);

$\mathrm{O}$ debate sobre qualidade existe, mas, está longe de ser cumprido;

TOTAL

$\begin{array}{cccc}6 & 50,00 & 9 & 37,50 \\ 5 & 41,66 & 7 & 29,16 \\ 1 & 8,33 & 4 & 16,66 \\ 1 & 8,33 & 4 & 16,66 \\ & & & \\ \mathbf{1 2} & \mathbf{1 0 0 , 0} & \mathbf{2 4} & \mathbf{1 0 0 , 0}\end{array}$

Que dimensões (aspectos/fatores) devem ser consideradas para a promoção efetiva da qualidade da educação?

Infraestrutura física e material (salas maiores; brinquedos; jogos; materiais didáticos);

Formação profissional (das professoras, das ADIs, das coordenadoras, das estagiárias);

Condições dignas de trabalho (salário digno, formação, redução de carga horária; materiais de trabalho);

Aspectos socioafetivos (relação família/escola; relações humanas/ comunicação);

Suporte aos alunos (assistência; alimentação, saúde, educação);

\begin{tabular}{cccc}
8 & 34,78 & 19 & 44,18 \\
6 & 26,08 & 10 & 23,25 \\
3 & 13,04 & 3 & 13,03 \\
1 & 4,34 & 1 & 4,34 \\
5 & 21,73 & 10 & 23,25 \\
$\mathbf{2 3}$ & $\mathbf{1 0 0 , 0}$ & $\mathbf{4 3}$ & $\mathbf{1 0 0 , 0}$ \\
\hline
\end{tabular}

TOTAL

Fonte: Coleta direta de dados, Lima (2016).

\section{O que os sujeitos entendem sobre qualidade da educação}

Os dados mostram que uma parcela significativa das entrevistadas, atribuem mais de uma resposta a compreensão sobre qualidade da educação. "Aquela que é boa (que tem eficiência; que tem excelência; tem eficácia; funciona perfeitamente) " foi considerada, pela maioria (65,85\%), a mais significativa. Em seguida, aparece com 46,42\% "É aquela

Revista de Administração Educacional, Recife, V. 1. № 2 - jul/dez. 2017 p. 88-105 
que oferece alimentação, saúde, bem-estar para as crianças" e, com 35,70\%, "Envolve estrutura física, material e pessoal qualificado". Sem desconsiderar uma parcela significativa que não soube responder $(32,13 \%)$ e outras menos citadas.

A qualidade da educação para a maioria dos sujeitos, conforme as categorias representadas, reflete uma visão ainda limitada e estritamente técnica, baseada em princípios de eficiência. Remete a conceitos e significados de qualidade, cujo enfoque reproduz a abordagem da qualidade defendida pelo sistema produtivo empresarial, enraizada nas teorias tecnicistas, mecanicistas e funcionalistas da teoria Taylorista do início do século passado.

Existem hoje, no campo específico da educação, contribuições na literatura para superação conceitual de qualidade nessa perspectiva. Segundo Cortella (2007, p. 9), qualidade em educação é um conceito historicamente construído e em disputa, mas cabe aos sujeitos políticos que atuam pelo direito à educação de qualidade especificar quais concepções almejam defender. Defender a qualidade da educação numa perspectiva democrática, legítima a todos, comprometida com a garantia do direito a educação para todos ou defendê-la na perspectiva do capital, como direito de poucos? Este é o grande desafio da educação e dos educadores.

A literatura acerca dos estudos sobre qualidade da educação demonstra que os educadores estão impregnados pelo ideário da campanha nacional pelo direito à educação com qualidade. Contudo, o discurso sobre a qualidade da educação da maioria dos profissionais da educação infantil participantes deste estudo restringe-se a significados mais estritamente técnicos e burocráticos. Segundo Carreira e Pinto (2007, p.21), este discurso caracteriza os debates sobre qualidade predominante na década de 90, incorporada a agenda da reforma educativa caracterizada como neoliberal. Reformas que foram influenciadas pelas agências multilaterais - Banco Mundial, Unesco e ONU - no controle das políticas sociais e de privatização da educação. Nesse período, a qualidade passou a ser vista como mera busca de eficiência, lema da área empresarial que penetra no campo educacional, cuja preocupação com a qualidade se fundamentava na eficiência visando resultados quantitativos.

Revista de Administração Educacional, Recife, V. 1. № 2 - jul/dez. 2017 p. 88-105 
Contrapondo-se a esta perspectiva, o discurso da qualidade na educação numa perspectiva democrática defende a qualidade como uma condição para todos e não para poucos. Pensar a qualidade nessa perspectiva significa compreender as desigualdades sociais, o compromisso com a inclusão cultural e social, o respeito à diversidade, a sustentabilidade, a democracia, sobretudo, a universalidade do direito a educação com qualidade. Nessa perspectiva, o conceito de qualidade da educação compreende não apenas a garantia de custos e de infraestrutura e equipamentos adequados, mas, também, a qualificação dos profissionais da educação, as condições de trabalho satisfatórias e bons salários, componentes indispensáveis para efetivação dos processos de ensinoaprendizagem.

Outro discurso acerca da qualidade da educação apreendido com base nas falas de 46,42\% dos profissionais da educação infantil, corresponde a percepção da qualidade da educação como sendo resultado do investimento na alimentação, na saúde e no bem-estar das crianças, conforme mostram os seguintes depoimentos: é atender as necessidades das crianças pobres da melhor forma possível, proteção, alimentação, saúde (Professora); "suprir o que as crianças não têm, comida, afeto, saúde (Auxiliar de Desenvolvimento Infantil).

Verifica-se, no conjunto das representações sociais, uma concepção de qualidade da educação como uma condição que vai proteger e de creche e pré-escola como lugar onde se assiste, alimenta, cuida da saúde e da guarda a criança pobre. Um entendimento de educação e de qualidade sustentado ainda pela visão assistencialista, de compensar a falta de tudo que as crianças pobres não têm.

Essas representações são ainda reflexos dos discursos sobre qualidade da educação infantil da década de 50 e 60 do século passado, fundamentado pela abordagem psicológica e da privação cultural. A primeira centra a discussão da qualidade da educação nos aspectos afetivos do desenvolvimento infantil e a segunda no atendimento nas necessidades de higiene, de alimentação e de saúde das crianças, baseado nos princípios da educação compensatória, considerando a criança pobre sempre em falta e a creche como compensadora de deficiências biopsicossociais e culturais.

Revista de Administração Educacional, Recife, V. 1. № 2 - jul/dez. 2017 p. 88-105 
Com a Constituição (1988) e a LDB (1996), as creches e pré-escolas passaram a ser reconhecidos como espaços sociais e educacionais legítimos a toda as crianças independentes de condição social. Entretanto, o que se constata neste estudo, baseado nas representações sociais das gestoras e das educadoras participantes da pesquisa, é que essas instituições, em particular de caráter público, governamental, apesar do avanço na legislação continuam ainda com a função de compensar deficiências.

\section{Como avaliam o debate sobre qualidade da educação no Brasil?}

Os resultados revelam que a maioria $(87,50 \%)$ das respostas se centra na afirmativa que o debate sobre a qualidade da educação existe na teoria, mas, não existe na prática (é utopia). Observa-se que as outras respostas, embora com outras palavras, têm o mesmo significado. As representações que os profissionais das instituições de Educação Infantil têm sobre os diferentes percursos seguidos pelo debate da qualidade na educação no Brasil parecem estar associadas diretamente a não efetivação das diretrizes legais que assinalam a melhoria da qualidade do atendimento a criança nessas instituições. As entrevistadas destacam: Eu vejo que falam muito em qualidade, mas, não se pratica, não vemos nada de qualidade, só descaso com a educação infantil (Auxiliar de Desenvolvimento Infantil); Qualidade para mim está só no discurso, nas leis, mas, não se cumpre (Auxiliar de Desenvolvimento Infantil); Está na teoria, no debate que é feito nas instituições públicas, mas, só funciona nas intuições privadas, nas públicas se perde no meio do caminho (Coordenadora pedagógica); Não existe, quando tem fórum do COMUDE, o prefeito passa por cima das decisões, manda um projeto fictício (Professora); Os conselhos de educação defende a qualidade da educação infantil, mas, só fica nas reuniões, nada acontece (Professora).

Essas concepções, visões e opiniões acerca do debate sobre a qualidade da educação não foram formuladas ao acaso, refletem o próprio debate do contexto histórico das creches e pré-escolas públicas no Brasil, fundado ao longo do tempo na luta dos movimentos sociais por equipamentos e serviços coletivos de atendimento a criança, público e de qualidade. Como ressaltam as protagonistas da educação infantil, "condições tantas vezes garantidas na legislação e não efetivadas, constatadas pela ausência ou pelas

Revista de Administração Educacional, Recife, V. 1. No 2 - jul/dez. 2017 p. 88-105 
limitações de oferta, infraestrutura física, materiais e humanas do atendimento público as crianças.

É importante reconhecer, segundo Campos, Fullgraf e Wiggers (2006, p. 87), que as diretrizes legais que apontam para melhoria da qualidade do atendimento a criança nas instituições de Educação Infantil não puderam ser traduzidas em efetivas medidas práticas. Segundo estas autoras, a distância entre a legislação e a realidade continua, infelizmente, a caracterizar a grande parte da educação infantil do país.

O resultado das respostas das entrevistadas é, portanto, compreensível, à medida em que reflete a realidade vivenciada pela maioria das instituições de Educação Infantil no Brasil. Pesquisa realizada pelo MEC no ano de 2010, em várias capitais do País e abrangendo 150 Centros de Educação Infantil, comprova esta realidade. O estudo visou avaliar a qualidade da Educação Infantil e evidenciou que as instituições apresentaram níveis de qualidade insatisfatórios nos diferentes aspectos investigados.

Os resultados também refletem - à medida que 70,82\% das entrevistadas não souberam responder à pergunta, ou não sabiam do que se tratava - a deficiência de conhecimento sobre o assunto em pauta. Do mesmo modo reflete a desinformação em relação a tendência que a qualidade da educação vem apresentando nas últimas décadas, sobremodo, a interpretação da qualidade da Educação Infantil como direito de todos e não de poucos, previsto nos documentos legais que tratam desta condição.

\section{Dimensões (aspectos/fatores) que os gestores e profissionais consideram para a promoção efetiva da qualidade da educação}

Os dados relativos a essa pergunta mostram um número de respostas maior do que o número de entrevistadas, uma vez que mais de um aspecto/fator importante para a promoção da qualidade da educação foi considerado. Para 78,96\% das entrevistadas, representadas pelas gestoras, coordenadoras pedagógicas, professoras e auxiliares de desenvolvimento infantil, a infraestrutura física e material - salas pequenas, falta de material didático, livros, jogos, brinquedos, leigos - são aspectos/fatores considerados mais importantes. Em seguida, 49,33\% consideram importante a formação profissional (das professoras, das ADIs, das coordenadoras, das estagiárias). Suporte aos usuários/as (assistência; alimentação, saúde, moradia) aparece na sequência como terceiro item mais

Revista de Administração Educacional, Recife, V. 1. № 2 - jul/dez. 2017 p. 88-105 
considerado para $40,64 \%$, tendo em conta a promoção efetiva da qualidade da educação. Os aspectos socioafetivos (relação família/escola; relações humanas/comunicação) e condições dignas de trabalho (salário digno, formação, redução de carga horária; materiais de trabalho) aparecem na sequência, em quarto e quinto lugares, respectivamente, com percentuais quase equivalentes.

Estes resultados confirmam, em grande parte, aqueles encontrados nas respostas dadas ao item 1 - quando se indagou sobre a visão que as entrevistadas têm sobre qualidade da educação - ao passo que valorizam como os mais importantes para a promoção da qualidade da educação aspectos /fatores semelhantes aos pontuados na resposta do item 1 . Verifica-se que há concordância entre fatores mencionados como os mais importantes estrutura física e material, seguidos de pessoal qualificado, alimentação, saúde - e a representação social que possuem sobre qualidade da educação.

Tomando como base o documento Indicadores da Qualidade na Educação Infantil, publicado pelo MEC (2009, p. 29), sete dimensões (aspectos/fatores) de qualidade são consideradas para avaliação da qualidade das instituições de Educação Infantil: planejamento institucional; multiplicidade de experiências e linguagem; interações; promoção da saúde; espaços, materiais e mobiliários; formação e condições de trabalho para professores e demais profissionais; cooperação e troca com as famílias e participação na rede de proteção.

Ao se desvendar as representações dos sujeitos constata-se o não ou pouco reconhecimento dessas dimensões. São instrumentos que as instituições devem usar para avaliar, com a participação de todos os segmentos que compõem a Educação Infantil e juntamente com a comunidade, a qualidade do atendimento prestado a criança em seus diversos aspectos - considerando as referidas dimensões - e, nessa direção, a começar dos problemas detectados coletivamente, buscar soluções visando melhorias das práticas pedagógicas e educativas, numa perspectiva participativa e democrática. No entanto, o que se constata é a não apreensão dessas dimensões no seu conjunto pelos profissionais da educação infantil, o que é preocupante.

A formação para professores e demais profissionais foi a segunda dimensão mais citada pelas entrevistadas, sendo inclusive recorrente no discurso das gestoras e das outras

Revista de Administração Educacional, Recife, V. 1. No 2 - jul/dez. 2017 p. 88-105 
profissionais. Apresenta-se como um dos maiores desafios a ser enfrentado pela Educação Infantil, conforme revelam as entrevistadas: Você deve eleger um conjunto de três pilares, qualidade dos professores no se refere à formação, salário e infraestrutura física (Gestora); Se não tiver uma política de organização e capacitação dos profissionais, nada acontece (Coordenadora Pedagógica); Formação continuada mais constante, pois faz tempo que a gente não tem capacitação nenhuma, não se atualiza (Professora);

Com base nesses depoimentos, é clara a preocupação das entrevistadas em chamar atenção para a relação entre a boa formação dos profissionais e o melhor desempenho das crianças na Educação Infantil. Parte-se do princípio de que instituições de Educação Infantil de boa qualidade possuem quadros de profissionais qualificados, com formação inicial e continuada adequada na área de Educação Infantil, com conhecimentos teóricos metodológicos consolidados acerca do cuidar e do educar, sobretudo, comprometidos com a aprendizagem dos seus alunos. A qualificação ou a capacitação, como transmitem as entrevistadas, do professor ou de outros profissionais que trabalham com os cuidados e educação das crianças, é vista como um importante aspecto/fator no processo de desenvolvimento integral e na efetivação do desempenho das crianças e, consequentemente, na garantia de uma educação de qualidade.

Campos, Fullgraf e Wiggers (2006, p. 118), fundamentados em pesquisa de revisão de estudos empíricos sobre qualidade da educação em instituições de Educação Infantil, afirmam que os desafios encontrados em relação à formação de professores da Educação Infantil são muitos. De fato, ainda existem muitos educadores sem a formação e a escolaridade mínimas exigidas pela legislação, como existe também a inadequação dos cursos de formação existentes em relação às necessidades de formação para Educação Infantil.

\section{CONSIDERAÇÕES FINAIS}

Embora o objetivo do estudo não tenha sido o de identificar as limitações das instituições de Educação Infantil, entraves generalizados são identificados tendo em conta as análises das concepções das profissionais da Educação Infantil acerca da qualidade da

Revista de Administração Educacional, Recife, V. 1. No 2 - jul/dez. 2017 p. 88-105 
educação. Entraves que vão além do não cumprimento da implementação dos Parâmetros Nacionais de Qualidade para Educação Infantil e da utilização dos Indicadores da Qualidade na Educação Infantil como instrumento de auto avaliação destas instituições propostas pelo MEC.

A análise dessa problemática sugere uma investigação mais aprofundada, uma vez que as instituições de Educação Infantil ainda revelam o caráter assistencialista compensatório atribuído a estas instituições ao longo de sua história e que as configuram do modo que ainda hoje o são. Apesar de todo o aparato legal, o padrão de qualidade da educação infantil vigente no atendimento a criança é centrada, principalmente, na insuficiência de recursos, na má qualidade do atendimento, na desvalorização e desqualificação do profissional, na ausência de cumprimento da legislação específica que garante o direito da criança a um atendimento de qualidade. Este é o entendimento que reflete a compreensão das gestoras e educadoras participantes da pesquisa acerca da qualidade da educação conforme mostram suas representações sociais.

O que se percebe na realidade é que, o avanço do debate sobre qualidade da educação infantil que resultou na construção de novas concepções centradas no desenvolvimento da criança, integrando outros aspectos além das demandas físicas e numa perspectiva democrática comprometida com as transformações sociais e com a melhoria da qualidade da educação como direito para todos, não significou mudanças efetivas nas políticas educacionais. Desconsidera-se a participação da família enquanto contribuinte e usuária dos serviços prestados por essas instituições e o direito da criança a um atendimento de qualidade que se efetive na perspectiva do seu desenvolvimento integral.

Para além do âmbito técnico (da eficiência e da eficácia) o conceito de qualidade deve ser pensado, principalmente, quando se toma o eixo da qualidade para educação, uma prática administrativa democrática, comprometida com a transformação social e com a melhoria da qualidade da educação, sobretudo, da Educação Infantil como primeira etapa da Educação Básica.

A formação dos/as profissionais da Educação Infantil requer conhecimentos que vão além das bases científicas do desenvolvimento da criança, do processo ensino aprendizagem e das práticas de cuidado e educação da criança, que abarquem as questões

Revista de Administração Educacional, Recife, V. 1. No 2 - jul/dez. 2017 p. 88-105 
políticas relacionadas aos direitos das crianças a educação com qualidade. A compreensão acerca dos avanços do debate da qualidade da educação por parte dos gestores públicos e dos profissionais da Educação Infantil são de fundamental importância para a sua adoção, implementação e resultados.

\section{REFERÊNCIAS}

BRASIL. Constituição da República Federativa do Brasil: promulgada em 5 de outubro de 1988. Brasília, DF: Senado Federal/Centro Gráfico, 1988. 292p.

ECA (1999). Estatuto da Criança e do adolescente. Lei n.8.069, 13 de Julho de 1990 e legislação correlata (recurso eletrônico) - 9.ed.-Brasilia: - Câmara dos Deputados. Edições Câmara, 2010. 207p.

Lei no 9394 de 20 de dezembro de 1996. Estabelece a Lei de Diretrizes e Bases da Educação Nacional. 1996. Diário Oficial da União. Brasília, DF, 1996.

Ministério da Educação e Cultura. Secretária de Educação Básica. Indicadores da qualidade na Educação Infantil. Brasília: MEC/SEB, 2009. 64p.

Ministério da Educação e do Desporto. Secretaria de Educação Básica. Parâmetros nacionais de qualidade para a educação infantil/Ministério da Educação. Secretaria de Educação Básica - Volume 1, Brasília, 2006.

Ministério da Educação e do Desporto. Secretária de Educação Básica. Política Nacional de Educação Infantil: pelo direito das crianças de zero a seis anos à educação. Brasília: MEC/SEF, 2003.

CAMPOS, M. M.; FÜLlGRAF, J. ; WIGGERS, V. Qualidade da Educação Infantil Brasileira: Alguns Resultados de Pesquisa. Cadernos de Pesquisa, v. 36, n. 127, jan./abr. 2006.

CAMPOS, M. M.; ESPOSITOI, Y. L.; BHERING, E.; GIMENES, A., N. B. Avaliação da qualidade da educação infantil. Cad. Pesqui. Vol. 41 n.142 São Paulo Jan./Apr. 2011.

CAMPOS, M. M. Entre as políticas de qualidade e a qualidade das práticas. Cadernos de Pesquisa. v.43 n.148 p.22-43 jan./abr. 2013.

CARREIRA, D.; PINTO, J. M. R. Custo Aluno - Qualidade Inicial: rumo a educação pública de qualidade no Brasil. São Paulo: Global: Campanha Nacional pelo Direito a Educação, 2007.

CORTELLA, M. S. Prefácio: Qualificar a qualidade, desqualificar a complacência. In: DAVOK, D. F. Qualidade em educação. Avaliação, Campinas; Sorocaba, v. 12, n. 3, p. 505-513, set. Sâo Paulo, 2007.

DOURADO, L. F.; OLIVEIRA. J.F. A Qualidade da Educação: Perspectivas e Desafios. Cad. Cedes, Campinas vol. 29, n. 78, p. 201-215, maio/ago. 2009.

Revista de Administração Educacional, Recife, V. 1. No 2 - jul/dez. 2017 p. 88-105 
GENTILI, P.; SILVA, T. T. Neoliberalismo, qualidade total e educação: visões críticas. $2^{\mathrm{a}}$ ed. Petrópolis, 2015.

HERÉDIA, V. B. M. Dilemas da globalização. In: Qualidade em educação: um debate necessário. Passo Fundo: Universidade Educação Básica. Série Interinstitucional, 1997.

MOSCOVICI, Serge. Representações sociais: investigações em psicologia social; traduzido por Pedrinho A. Guareschi. 11ed. - Petrópolis, RJ: Vozes, 2015.

MOSS, P. Para além do problema com qualidade. In: MACHADO, Maria Lúcia de A. (Ed.). Encontros e desencontros em educação infantil. São Paulo: Cortez, 2002.

PREFEITURA DO RECIFE. Plano Plurianual para o Período de 2014/2017. Recife, Outubro, 2015.

RABELO,J; SEGUNDO, M.D.M; JIMENEZ,S. Educação para todos e Reprodução do Capital. REV, Trabalho Necessario, ano 7, nº, 2009.

SARAIVA, J. M. Perfil do Trabalhador do setor de Nutrição e Saúde de Creches Públicas da Cidade do Recife - PE. Dissertação (Mestrado). Programa de Pós-Graduação em Nutrição (área de concentração Saúde Pública), Universidade Federal de Pernambuco, Recife, 1999.

A lógica do capital e do estado na provisão dos meios de consumo coletivo: uma experiência de responsabilidade social no campo da assistência a criança. 2009. Tese (Doutorado). Programa de Pós-Graduação em Serviço Social, Universidade Federal de Pernambuco, Recife, 2009.

UNICEF. Fundo das Nações Unidas para a Infância, Relatório Situação Mundial da Infância, UNICEF, Nova 2008. https://www.unicef.org/publications/files/SOWC_2015_Summary_Portuguese_Web.pdf

ZABALZA, M. Qualidade em Educação Infantil. Porto Alegre: Artmed, 1998.

Revista de Administração Educacional, Recife, V. 1. No 2 - jul/dez. 2017 p. 88-105 